${ }^{1}$ Centro de Bioética, Facultad de Medicina Clínica Alemana-Universidad del Desarrollo. Santiago, Chile. aEstudiante de Medicina, Facultad de Medicina Clínica Alemana-Universidad del Desarrollo. Santiago, Chile. ${ }^{\mathrm{b}}$ Ayudante-alumno Centro de Bioética UDD.

Este trabajo no recibió financiamiento. Autores declaran no tener conflictos de interés.

Recibido el 29 de julio de 2020, aceptado el 14 de octubre de 2020.

Correspondencia a: Juan Pablo Beca Centro de Bioética. Facultad de Medicina Clínica Alemana-Universidad del Desarrollo. Av. Las Condes 12461 Torre 3, Of. 202. Las Condes, Santiago. jpbeca@udd.cl

\section{Rol del estudiante de medicina en el acompañamiento de los pacientes: reflexiones desde una vivencia}

\author{
DEBORAH FARAGO ${ }^{\mathrm{a}, \mathrm{b}}$, JUAN PABLO BECA ${ }^{1}$
}

We share the experience of a clinical relationship that arose between a medical student and a patient hospitalized due to a SARS-CoV-2 pneumonia. The analysis of this experience and the discussion of medical students' possible role in patient care suggest that they should be included as members of the health care team during their clinical practice. This would mean a positive contribution for both the patients' care and the students' learning experience.

(Rev Med Chile 2020; 148: 1328-1330)

Key words: Education, Medical; Patient Care Team; Students, Medical.

$\mathrm{E}$ n base a la experiencia de la relación clínica establecida entre una interna de medicina, autora de este relato, y un paciente durante la pandemia de COVID-19, se narra la relación de ayuda y de acompañamiento generada. A partir de esta vivencia, se analizó el posible aporte de acompañamiento que pueden ofrecer los estudiantes a los pacientes durante su práctica clínica. Se analiza esta experiencia y si los estudiantes podrían ser incluidos como parte del equipo de salud con un rol de acompañamiento, el cual enriquecería su aprendizaje, beneficiaría a los pacientes y podría aliviar a los equipos tratantes.

\section{Una vivencia significativa}

En mi condición de interna voluntaria de medicina durante la pandemia de SARS-CoV-2, conocí a un paciente en su tercera semana de hospitalización. El paciente, de 69 años, tenía antecedentes de hipertensión arterial, insuficiencia cardíaca, fibrilación auricular en tratamiento con anticoagulación oral, y diabetes mellitus 2 no insulino-requirente, con daño de órgano blanco. Después de consultar al servicio de urgencia por disnea de pequeños esfuerzos de un día de evolución, fue hospitalizado en la Unidad de Medicina Interna. Ingresó hemodinámicamente estable, taquipneico, saturación en sangre con $\mathrm{O}_{2}$ ambiental de $82 \%$ afebril, requiriendo apoyo con oxígenoterapia. Una tomografía computada (TAC) de tórax evidenció un foco de condensación extenso en el campo pulmonar derecho asociado a derrame pleural bilateral. Una reacción de polimerasa en cadena (PCR) para SARS-CoV-2 resultó negativa. Se hospitalizó para tratar una neumonia bacteriana con antibióticos y oxígenoterapia. En su séptimo día de hospitalización, el paciente evolucionó con deterioro de la función respiratoria, por lo que se solicitó una nueva imagen que mostró un patrón de vidrio esmerilado bilateral, con gran compromiso del parénquima pulmonar, asociado a un foco de condensación derecho en regresión y derrame pleural bilateral, impresionando compatible con neumonia por 
COVID-19. Una segunda PCR para SARS-CoV-2 fue negativa. Se continuó con terapia de soporte, logrando una buena evolución que permitió el retiro de oxígenoterapia. Fue dado de alta tras 25 días de hospitalización.

En mi primer encuentro con el paciente, él se encontraba silencioso, respondía de manera mínima a las preguntas y no quería establecer contacto. Lo que sí mencionaba, en forma reiterativa, era que nadie acudía cuando llamaba repetidamente por necesitar ayuda. Intenté explicarle que lo comprendía, le pedí disculpas y le expliqué que, dada la contingencia actual, el personal tenía muchos pacientes y gran sobrecarga de trabajo. Le dije que esa semana estaría yo de interna y que intentaría ayudarlo en sus necesidades, en la medida de lo posible. Fue claro que él no creía que pudiera ser así. Durante el día pude ver en varias ocasiones que la atención se retrasaba mucho desde que el paciente solicitaba alguna asistencia, por razones entendibles, dada la sobrecarga de trabajo del personal, por lo que esto no implica una crítica sino una realidad.

Partí mi segundo día entusiasmada en poder aportar no solo en el trabajo administrativo que se requería, sino también en apoyar emocionalmente a los pacientes. En mi interacción con el paciente que relato, lo noté más desanimado que el día anterior. Cuando terminé de examinarlo, decidí aprovechar la oportunidad del momento para acercarme más. Durante el examen físico noté que el paciente tenía las manos frías, lo cual usé como pretexto para intentar una conversación más humana. Entonces, al finalizar el examen físico, tomé su mano y le pregunté sobre sus manos frías y le pregunté si sentía frío, aún muy desanimado, me respondió que no, que siempre tenía las manos frías. Decidí permanecer a su lado en silencio, recordando una técnica de acompañamiento espiritual. Luego de más o menos 40 segundos de mutuo silencio, el paciente me comenzó a hablar. Debo mencionar que durante esos segundos se mantuvo apretando mi mano, una manifestación física de la cercanía y empatía que evidentemente necesitaba. Cuando comenzó a hablar, lo primero que dijo fue que estaba cansado de estar en el hospital y contó que el día anterior había estado por más de 10 horas pidiendo que lo muden. Me dijo lo incómodo que estaba, y que quería irse a su casa para estar con su familia. Luego me dijo que no todos tenían una buena disposición con los pacientes, que nadie le ayudaba a "hacerse los puffs", y que no le gustaba la comida. El paciente habló largamente y se descargó emocionalmente. Era lo que en su interior necesitaba y es lo que, desafortunadamente, el equipo de salud no le había podido brindar, por las circunstancias en las cuales nos encontramos.

Como interna de medicina tengo pacientes asignados por el docente a cargo, los cuales son muchos menos que los que tienen a su cargo los médicos, enfermeros y técnicos paramédicos. En esta situación de pandemia, los internos tenemos menos carga asistencial que el personal de salud. Por esta razón, tras mi experiencia con este paciente, me pregunté si nosotros, como internos o como alumnos, podríamos tomar un rol activo en contribuir en el acompañamiento de los pacientes. Uno de los fines de la medicina es "la atención y la curación de los enfermos y los cuidados a los incurables"'. En una pandemia en la cual los pacientes no pueden ser visitados por sus familias, con servicios de salud saturados y sobrecargados, frecuente agotamiento del personal de salud y con estrictos protocolos de EPP, el necesario rol de cuidado se torna aun más difícil. Recibir este cuidado es una necesidad y un derecho de los pacientes como personas, y brindarlo es una obligación de los profesionales de la salud. El interno se torna así en un potencial actor del equipo de salud, aprovechando cada momento dentro de la sala para, no solo apoyar en "lo médico", sino también en el aspecto emocional y espiritual intrínseco de cada ser humano. Cabe recordar que en situación de enfermedad la persona vive una crisis existencial y se vuelve más frágil, y que esta condición aumenta considerablemente en situación de pandemia.

\section{Discusión}

Hay escasas referencias al rol del estudiante de medicina en el acompañamiento del paciente. En una investigación previa se encontró que los médicos consideran que el alumno no representa un aporte al equipo de salud, aun cuando su presencia sirve para mejorar la calidad de trabajo de los docentes ${ }^{2}$. Por otro lado, algunas enfermeras valoran el rol comunicacional del estudiante, pero consideran que todavía no forma parte del equipo de salud. Esta visión limita las posibilidades de acompañar al enfermo que puede realizar 
el estudiante de medicina quien, al tener más tiempo disponible, puede contribuir a mejorar el cuidado del paciente. Más aun en tiempos de pandemia, con equipos de salud sobrecargados por el mayor número de pacientes, el interno podría ser considerado como un recurso útil y eficiente para complementar esta importante función: el acompañamiento.

En cuanto a la visión de los pacientes, se ha descrito que consideran que el estudiante de medicina suele brindarles más tiempo de atención e interés ${ }^{3,4}$, por lo que, en general, tienen una predisposición positiva hacia su participación en el equipo clínico. Algunos se sienten parte del aprendizaje de los futuros médicos al relatar su experiencia personal sobre sus patologías ${ }^{4}$, tornándose así en un recurso para la formación del estudiante. Esta mirada holística del paciente, cuya condición tiene un significado particular por el hecho de tener una historia y un mundo por detrás, es esencial en el quehacer de un buen médico. Considerar al paciente como experto en su condición se torna en un aporte esencial en la educación médica. Incluir al estudiante de medicina en el equipo clínico en un rol de acompañamiento y escucha maximizaría su aprendizaje. La inclusión del estudiante en el equipo clínico sería, por lo tanto, beneficiosa para el paciente y para el estudiante, creándose una forma de alianza con beneficio mutuo.

Algunas escuelas de medicina han descrito este fenómeno en la pandemia de COVID-19: los estudiantes de medicina están dispuestos y ansiosos por ayudar ${ }^{5}$. Los alumnos de medicina constituyen un recurso que hasta ahora ha sido poco utilizado en esta pandemia. Especialmente los internos, quienes tienen mayor conocimiento clínico y del funcionamiento del hospital ${ }^{5,6}$, podrían aliviar el trabajo de otros integrantes del equipo de salud que en estos momentos se encuentra sobrecargado ${ }^{6,7}$. Se han planteado diversas propuestas sobre el rol que podrían cumplir los estudiantes de medicina en el escenario de pandemia, la mayoría de las cuales se refieren a refuerzo en testeo, seguimiento de contactos y en ayudas a la comunidad ${ }^{5,7,8}$. Más aun, nacional e internacionalmente, muchos estudiantes de medicina se han organizado para colaborar como voluntarios $^{5}$. Este enfoque asistencial, muchas veces producto de una inquietud moral, debería constituirse más allá de una ayuda técnica, en un rol complementario y esencial de acompa- ñamiento al paciente. Para esto no basta tener la disposición y posibilidad de ayudar, sino que debe establecerse un concepto claro y directo de que el acompañamiento del paciente es parte de las tareas que debería asumir un interno. Para este efecto es necesario fortalecer los cursos de comunicación, Bioética y humanidades en los ramos preclínicos de la carrera y establecer, como parte del currículum, diálogos de internos con docentes clínicos, bioeticistas y psicólogos, para fortalecer esta arista fundamental de la práctica clínica. Cabe recordar que más que una ciencia, la medicina es el arte que busca el mayor bien del ser humano, considerando siempre la totalidad de este en un sentido más amplio que lo somático.

\section{Referencias}

1. Hanson MJ, Callahan D. The Goals of Medicine: The forgotten issues in health care reform. Hastings Center Studies in Ethics series. NY, USA, 2000. Versión en español: Fundación Víctor Grífols i Lucas. Los fines de la medicina. Barcelona, España. Cuadernos de la Fundación Víctor Grífols i Lucas No11; 2004.

2. Beca JP, Gómez M, Browne F, Browne J. Los estudiantes de medicina como parte del equipo de salud. Rev Med Chile 2011; 139 (4): 462-6.

3. Beca JP, Browne F, Valdebenito C, Bataszew A, Martínez MJ. Relación estudiante-enfermo: Visión del paciente. Rev Med Chile 2006; 134 (8): 955-9.

4. Jackson A, Blaxter L, Lewando-Hundt G. Participating in medical education: views of patients and carers living in deprived communities. Medical Education 2003; 37 (6): 532-8.

5. Soled D, Goel S, Barry D, Erfani P, Joseph N, Kochis $\mathrm{M}$, et al. Medical Student Mobilization During a Crisis: Lessons From A COVID-19 Medical Student Response Team. Acad Med 2020; 10.1097/ ACM.0000000000003401 (en prensa). Disponible en: www.pubmed.cl [Consultado el 22 de junio de 2020].

6. Stokes DC. Senior medical students in the COVID-19 response: an opportunity to be proactive. Academic Emergency Medicine 2020; 27 (4): 343-5.

7. Miller DG, Pierson L, Doernberg S. The Role of Medical Students During the COVID-19 Pandemic. Annals of internal medicine 2020, M20-1281 (en prensa). Disponible en: www.pubmed.cl [Consultado el 22 de junio de 2020].

8. Bauchner H, Sharfstein J. A bold response to the Covid-19 pandemic: medical students, national service, and public health. JAMA 2020; 323 (18): 1790-1. 